\title{
Suspending the Habit Body through Immersive Resonance: Hesitation and Constitutive Duet in Jen Reimer and Max Stein's Site-Specific Improvisation
}

\section{Rachel Elliott}

There is increasing appreciation for the role that location plays in the experience of a musical event. This paper seeks to understand that role in terms of our habitual relationships to place. I ask how being musical somewhere can expand and transform our habituated comportment there, an inquiry sparked by the theory and practice of the late experimental music pioneer Pauline Oliveros. Grounded in Maurice Merleau-Ponty's phenomenology of embodiment, I argue that the site-specific improvised performances of Jen Reimer and Max Stein invite audiences into transformed relationships with places they habitually encounter. With sustained comparisons to the centrality of deep listening in Pauline Oliveros's lifetime of sonic innovation, and frequent reference to Alia Al-Saji's reception of Merleau-Ponty's account of the habit body, this paper contends that such site-specific improvised performances can elicit a sort of hesitation in our everyday style of sensory-motor conditioning, and, concomitantly, awaken a layer of sensory living amenable to radically new sonic and behavioural configurations.

\section{The Subtle Immensity of Jen Reimer and Max Stein}

[T]aking performance out of the concert hall paradigm [...] its basic trait is enclosed space. Sound from the outside world is shut out intentionally for exclusive focus on the music being performed. In contrast, my paradigm is to perform in open space and include everything that is sounding. (Oliveros, "My 'American' Music" 230)

It was at Square-Victoria Metro Station in downtown Montreal that Jen Reimer and Max Stein crossed paths in 2008. Without the money to rent a dedicated practice space, Jen Reimer frequented the reverberant rotunda at night in order to play the french horn. Max Stein, at the time an emerging soundscape artist, wound up at the rotunda while conducting field research leading up to the creation of the Montréal Sound Map. The pair quickly recognized a shared artistic sensibility.

In June 2011, Reimer and Stein performed together in the Saint-Urbain Underpass as part of the Suoni per il popolo music festival. The Underpass runs below and perpendicular to the CN railway, dividing the gentrifying Mile-End from the largely industrial Petite-Patrie. It is a contested node in the pattern of local traffic, creating tensions between the $\mathrm{CN}$ rail line, the police, and the pedestrians seeking to cross the tracks on foot.

Reimer and Stein's performance in this fraught location used the electrical hum from the fluorescent security lights as a tonic orientation for the improvisation. Reimer played long sustained pitches on her french horn, which drew out the resonant frequencies of the tunnel and accentuated their complex overtones and feedback patterns; the reverberation produced was thick and immersive. Stein, in live-time, electronically manipulated modified field-recordings made in the underpass at an earlier time, amplifying them and projecting them into the space through a set of speakers. The cars that continued to pass as they played became aleatory instruments and contributed integrally to the performance.

In a more recent cluster of work titled Sounding the City, Reimer and Stein created a series of site-specific installations navigable through an online interactive map and virtual archive. One of 
the installations was contiguous with the Saint-Urbain Underpass, occurring in an open green space locally referred to as Le Champ des Possibles-a mixed use area of ambiguous proprietorship bordered by the $\mathrm{CN}$ rail line to the north, two textile factories, and Avenue HenriJulien to the east. ${ }^{1}$ On the other side of Henri-Julien, as it intersects with Avenue du Carmel, lies an active monastery, Moniales carmélites de Montréal, ${ }^{2}$ which understands itself to be "une source qui coule silencieusement au milieu de la cité."3 At the noon hour, however, their spring flows more amply; their chiming bells sail over the stone walls of the monastery and mingle with the sounds of screeching locomotives and shift-change alarms among the grasses and poplars in the Field of Possibilities. For Sounding the City, Reimer and Stein recorded this environment, then used a filter bank to modify the recordings in a manner emphasizing resonant frequencies. They played these modified recordings back out into the open green space using surface transducers, effectively, to paraphrase Stein himself, making the textile factories into a set of speakers. Listeners arrive at the installation by following the online map, or else come upon it par hasard.

\section{Hesitating at the Juncture Between Subject and World}

Reimer and Stein's audiences already have ways of being in these places-habitual styles of comportment related to these spaces, either in particular or as a type. Given the nature of the locations in which Reimer and Stein perform, these habits would pertain primarily to transportation and commuting, and would be characterizable by their instrumentality-they are nearly exclusively a means of arriving elsewhere, and not actions that are valued or thematized in their own right. We can clarify the nature and importance of Reimer and Stein's intervention into these forms of habitual comportment if we appeal to the idea of the habit body developed by existential phenomenologist Maurice Merleau-Ponty in the Phenomenology of Perception.

Merleau-Ponty identifies the habit body as the seat of our intentionality, which is our capacity to have experiences of a clear and distinct world rich in detail (Phenomenology 137-139). ${ }^{4}$ The habit body acquires its powers to discern its situation through repeated exploratory engagement with it. The strengthening of our perceptual faculties occurs in tandem with the dawning of recognizable, repeatable forms: subject and object are co-arising. Calling attention to the way that our perceptual faculties are built up over time through the acquisition of habit demands noticing that our perceptual powers are not immutable. Neither, however, is changing them merely a matter of conscious willing. Acquiring a new appendage or changing the environment are not sufficient by themselves to transform our habit bodies. The effects of such interventions on the perceptual system cannot be immediate, if we understand the habit body as an achievement attained through repeated integrative engagement with challenging perceptual situations (which are challenging precisely to the extent that the habit body has not yet fully adapted to them).

Taking seriously the co-arising of subject and world makes appreciable the difficulty of transforming the habit body. When we change the habit body, we change our perceptual experience as well. This can be disorienting as well as personally and interpersonally risky. Attuning ourselves to new perceptual arrangements means forgoing the clarity and regularity that we enjoy in virtue of our matured sensory conditioning. In addition to perceptual confusion about the external world, certainty about our own personal coherence is likewise thrown into doubt. Our familiarity with ourselves, like the experience of a stable world around us, also depends on the habit body as our general means of being in the world. Relatedly, it is through this habit body that others recognize us as human persons. Putting our legibility in relation to others in question is to risk losing social recognition and to court exclusion or abjection instead. 
To do so at the very same time that one's own basis for stable perceptual experience is indeterminate is a high level of vulnerability, indeed.

The co-arising of habit and a perceptual world, furthermore, entails that the habit body is riveted to a certain style of place; the place where we "cut our teeth," to oddly employ a familiar expression. While the habit body is a transposable pattern that allows, for instance, an organist to play in an unfamiliar church (Merleau-Ponty, Phenomenology 145), its pairing with the style of its generative environment can lead to restricted perception of the sort well and famously characterized by Abraham Maslow: "it is tempting, if the only tool you have is a hammer, to treat everything as if it were a nail" (15). This is to say that while the habit body enables us to treat similar situations similarly, it can prevent us from approaching a situation freshly, or taking stock of its complexity.

Interestingly, some scholars, such as Shannon Sullivan, have argued that because "[h]abit can never be separated from its environment" (2), a veritable change of environment is required in order to transform the habit body. But what would prevent a new environment from serving as just another nail? Changing environments only works to transform the habit body when an opening to new forms of comportment is available. The all-important question, then, is how such an opening can come to be, given the many pressures to maintain habitual perceptual comportment. It is here that we would like to locate the role of improvisations tailored to particular places in expanding our habituated forms of perception. As we shall see, both the improvised character of these performances and their site-specific nature are fundamental to the way such openings are made possible.

Merleau-Ponty scholar Alia Al-Saji points to hesitation as the means through which we realize both the shape of our habits and the possibility of acting otherwise. For her, hesitation is a way of instigating a pre-intentional state where the world appears not clear and distinct but indeterminate, characterized by nascent suggestibility. It is here that we forge new embodied initiatives, responding to inchoate solicitations that tease from us fresh styles of sensory-motor schematizations. In Al-Saji's words, "to hesitate is to feel one's way tentatively and receptively [...] so that the futures it encounters were not those initially anticipated" ("Phenomenology" 143). Al-Saji conceives of hesitation as a sort of interruption between "excitation and response" ("Phenomenology" 143). Using more technical phenomenological language, she writes: "Hesitation is both the ontological ground that makes possible transformations in habit, and the phenomenological opening that can be utilized and supplemented for such change to take place" ("Phenomenology" 149).

Such an opening, however, must be "taken up for new possibility to be created" ("Phenomenology" 149). And this necessity, Al-Saji continues, demands "indirect strategies for fostering hesitation," such as "the creation of situations and attachments that bring hesitation about, as well as attention to ways of holding hesitation open and allowing it to become productive" ("Phenomenology" 149).

Arguably, Pauline Oliveros's decades-long practice of deep listening hones hesitation and its transformative potential in rich and studied ways. Her composition, electronic innovation, improvisation, and ensemble performances, as well as her theoretical writing and teaching, variously point to an understanding of her Deep Listening practice that finds strong resonance with what we have been articulating here. Let us first consider Oliveros's work before bringing the theory we have been laying out to bear on the installations of Reimer and Stein. As we shall see, both of the steps in Al-Saji's account of transformation are discernable in this nature of work: the opening up phase, on the one hand, and the taking up phase, on the other. Hesitation, 
which engenders the opening up, takes place when we attend the performance. These performances occur in locations that elicit ingrained behavioural habits, habits other than those we use in a performance venue. When we treat such everyday spaces as performance venues, our engrained habits connected to that space in the everyday are, on the one hand, conjured (by the familiarity of the location), and, on the other, suspended (by the state of exception instituted by performance). The second step in the transformation occurs within the hesitation engendered by the performance as such; the taking up phase occurs in the specifically improvisational musicking itself.

\section{Pauline Oliveros and the Pre-Habitual Body}

In her article "Improvising Composition: How to Listen in the Time Between," Oliveros articulates a fascination with the domain of pre-activity. Oliveros references neurophysiologist Benjamin Libet's idea of "evoked potentials" ("Improvising Composition" 85) -the body's readiness to act prior to our conscious awareness of an intention to act. According to Libet, the body is poised to (neurologically) "anticipate an action" prior to our consciously intending to do it; we trace out a path of action within our bodies in a pre-conscious way. Recast in the phenomenological language that we have been advocating here, we would, with Husserl, understand this preperceptual readiness to be conditioned by a pre-objective "motive" or "allure" (Husserl 183; 202). Merleau-Ponty calls this affective allure "a vague beckoning" (Phenomenology 214). Both Husserl and Merleau-Ponty provide an explanation for the body's preparedness to act before a conscious intention to do so is recognized. The ideas of "motive," "allure," or "vague beckoning" accentuate that action potentials are the correlate of an external provocation, vaguely sensed. Understanding action potentials in this way, as prepersonal sensitivity to the beckoning world, provides an answer to Oliveros's concluding musings about them in this essay: "What remains mysterious is how the myriad decisions and actions that make the music happen during the space between the readiness potential and the performing are coordinated so spontaneously ("Improvising Composition" 88).

Spontaneous coordination of action potentials is only mysterious if we understand them as private impulses belonging to individual agents. However, if we conceive of these action potentials as drawn in us from the outside toward a dawning aspect, then it is easy to see why action impulses can be coordinated with such apparent spontaneity. This worldly solicitation is an open call; when action potentials fly together like a murmuration of starlings, it is because they are responding to a common motive in the environment. In Reimer and Stein's work, it is this open call that is emphasized, rather than the response to it.

We see this emphasis on the receptivity within the activity of music in "The Intertwining - The Chiasm," a chapter from Merleau-Ponty's late work titled The Visible and the Invisible.

Describing the sense that we are following or chasing something as we play, Merleau-Ponty writes: "The performer is no longer producing or reproducing the sonata: he feels himself, and the others feel him to be at the service of the sonata; the sonata sings through him or cries out so suddenly that he must 'dash on his bow' to follow it" (151).

It might be objected that this image can only befit musical forms like sonatas which can exist and be known in advance of being played, but that is not apt with regards to improvised sound installations which, the idea goes, cannot be "followed" since their form does not precede the performance of it. To this we would respond that while the form of the music is indeed being created in live-time as it is performed, there is still a motive or affective allure calling to the performer. 
We would point to the space between the produced sound and the returned sound as the motive in the sort of music we are considering here. Listening to the length and quality of a place's reverberation is akin to the sonata pursued by the musician in this passage by MerleauPonty. Such listening would be most interesting in non-traditional venues where there is a genuine unknown in terms of how the place will respond to performance. This is precisely what we do find in the work of Reimer and Stein, as well as in Oliveros's work, as we shall see below. When sound returned to us through reverberation, delay, and resonance provides the motive for renewed sonic gestures, we observe in full evidence what Husserl calls the "constitutive duet being played" between perceiver and perceived in every perceptual process (56). This duet is taking place at the level of what Alia Al-Saji calls sensory life ("A Past" 47), in what MerleauPonty calls the prepersonal body (Phenomenology 165). Awakening to this prepersonal sensory duet, can, we affirm, transform the habit body and the perceived environment simultaneously through an intervention of the sort Al-Saji envisions in hesitation. Here is more detail about what hesitation entails: "the ability to be affected, to be touched, by that which lies beyond or beneath [...] habitual objectifying schemas. It is the openness to unanticipated (and not immediately cognizable) difference - an affective openness that [...] grounds the dynamic and improvisatory character of perceptual habits [...]" ("Phenomenology" 140).

The habit body is formed from this layer lying "beyond or beneath," this openness to what is not immediately cognizable. This layer, however, is not left behind once the habit body is developed and gains its relative autonomy; it is maintained. It is here that action potentials and the vague beckonings that elicit them have their being.

Putting the matter in this way, however, generates an epistemological problem. If the vague beckonings that elicit action potential in the body are pre-consciously registered, as they are understood to be, how do we come to be aware of them? In other words, if such bodily readiness definitionally precedes our conscious awareness of them, how can we be aware of them at all?

It is true that while wrapped up in habit, prepersonal solicitations are largely too subtle to be sensed. This is one reason why we have trouble shifting away from habits-we suspect there is nothing else to do, no other possible way to act. As Al-Saji's determination of hesitation suggests, however, there are ways of bracketing or suspending our habitual perceptual patterns. One way of doing so, we contend, is through the sort of musical practice discussed here and exemplified by Pauline Oliveros, Jen Reimer, and Max Stein. These immersive sitespecific improvisations bring the prepersonal layer of sensory life into relative explicitude; by suspending conditioned reactions to the environment in a performance situation, it becomes possible to sense and select less trodden paths of suggested movement, through improvising based on the sounding environment. The reverberant sound is what creates new suggested pathways, and the improvisers create new possibilities by following them and taking them up. Reimer and Stein, as we have seen, create instances where the motive for further sound making is instigated by their own playing, returned as an echo or reverberation coloured by the location of play. In these cases, the motive or worldly solicitation can be said to be an affordance of the space-the non-identity between what is played and what is heard in the reverberation. Looking at Pauline Oliveros's lifetime of work will give these ideas greater vividness.

\section{A Brief Genealogy of Pauline Oliveros's Aesthetic Consciousness}

When Oliveros was about eleven years old, she, along with a hundred other accordions, performed The Marines' Hymn at the Sam Houston Coliseum (Mockus 114). The experience, 
she says, "turned my attention to the timbre of the instrument and of many instruments sounding together simultaneously" ("Accordion" 156). The simultaneity and timbre that stick out in Oliveros's memory about the playing are features of the sound reflected back to her by the Coliseum's reverberant walls. In a conversation that took place in the spring of 2017, the late conductor and music scholar Eleanor Stubley theorized that it is precisely through such architectural refraction that the action of multiple individual sound producers can be heard as one, rather than as a cluster of unsynthesized, co-located occurrences. We could understand this early experience in Oliveros's music career as part of an emerging attention to the receptive activity of places containing sound. In 1953, Oliveros recorded the sounds outside the window of her San Francisco apartment using an Eico tape recorder that her mother gave her as a birthday present. In her words: "I learned that the microphone was hearing sounds that I missed while listening during the recording" ("Tripping" 123). She was listening to the listening of the machine.

Likewise, Oliveros's celebrated electronic works such as Time Perspectives (1959) and I of IV (1966) were made in live-time as Oliveros payed close attention to how the various tape machines and signal processors she was using received the frequencies she initiated. Their audible reception and modification of them provided the stimulus for Oliveros's further sonic initiatives. Speaking about the creation of $I$ of IV in an interview with Alan Baker from 2003, Oliveros says:

I performed that piece in the studio in real time. In the studio at the University of Toronto there was a four-channel system. As I played this piece, it was in four-channel and I was in the middle of it, but the documentation of the performance was stereo. Incidentally, there was no mixer, so I was just patching signals. The truth of that piece is that no one could hear it now the way I heard it as I performed it. I think there was one other person present when I made that piece. And that piece has what we refer to as a "screamer" in it-there's an incredible melody that comes out. I remember when it happened, and it was very surprising and wonderful. I was laughing as it happened. All of that is kind of the history of the piece, but those tracks, those two extra tracks of the four-channel system were virtual, and they don't exist except in the mix that resulted in the recording of the recording in the second machine. (Oliveros, Interview with Alan Baker)

The series of text scores called Sonic Meditations that Oliveros composed in the 1970s were crafted, as she writes, "to provide attentional strategies for the participants. Attentional strategies are nothing more than ways of listening and responding in consideration of oneself, others, and the environment" ("Interactive" 6). This is to say that her word scores were guides for the listening of the performers: the score was the very content of their listening, as directed by the text scores.

Oliveros's Deep Listening Band formed through a 1988 performance in the Fort Worden Cistern with Stuart Dempster and Panaiotis; ${ }^{5}$ the forty-five second delay created by the walls of the cistern stole the show. Oliveros writes: "I treated the cistern as a huge delay processor even though all of the sound was acoustic" ("Accordion" 160). In Crone Music (1989) and thereafter, Oliveros continues to format her Expanded Instrument System (EIS), which she had been developing since 1965. Whether in its analogue, digital, or eventually algorithmic manifestation, $E I S$ is designed to create "the illusion of one space morphing to another" ("Improvising with Spaces" 200), as Oliveros plays the accordion with it. Through EIS, Oliveros is able to

tamper with the container of music in imaginative ways. The walls of a virtual acoustic space created electronically can expand or contract, assume new angles or virtual 
surfaces. The resulting resonances and reflections changing continuously during the course of a performance create spatial progressions much as one would create chord progressions or timbre transformations (changing the tone quality of an instrument while performing a single pitch). ("Virtual" 20)

The EIS' imperative (and improvisation imperative) is to listen and respond: spatial relationships and progressions are as important as the traditional parameters of music (melody, harmony, rhythm, timbre). ("Expanded" 218)

All of these phases in Oliveros's career accentuate a form of listening to the reception of a sound, whether that sound is received by the walls of a cistern, a delay processor, or another human being. This form of attention could be described as listening to the listening (if we do not presume that only human beings can listen), a formulation resonant with the way MerleauPonty's ideas develop towards the end of his life.

\section{Sonic Reversibility and the Later Merleau-Ponty}

In his "Working Notes" to the uncompleted portion of The Visible and the Invisible, MerleauPonty develops the idea of reversibility as a description of being, or basic ontology (Visible 263). An enriched conception of reversibility-listening to the listening-seems possible if re-cast in an understanding of Oliveros's work. Although reversibility is mainly discussed in terms of sight and touch (Visible 133-134), Merleau-Ponty has the aural sense in mind, too:6 "The chiasm, reversibility, is the idea that every perception is doubled with a counter-perception [...] one no longer knows who speaks and who listens. Speaking-listening, seeing-being seen, perceivingbeing perceived [...] Activity = passivity" (Visible 264-265).

Listening to the listening means not only paying attention to how others are perceiving a sound, but also how they are sounding their listening. Entailed in the idea of listening to listening is the sense that listening is itself audible, something that can be listened to.

We can observe this audibility of listening in machines, such as recording devices. As Oliveros notes, hearing what a machine hears expands our hearing too. Oliveros attributes an "openness and adventurousness" to younger audiences due to "the availability of audio and video recordings of performances, and of immediate playback for the performers" ("Tripping" 123). This enables the performer to hear what they did not hear-what was precluded by engrained habits of perception-like Oliveros did with the tape recorder in her window.

In listening for a sound's reception by various human and non-human reverb chambers, we have necessarily created a greater amount of time in which to respond to that sound stimulus. In other words, to put the point rather baldly, listening back to the recording of oneself performing puts more time between that performance and the next, and it literally opens up new possibilities for the next performance if taken up. Put less baldly, listening to the response of an audience while playing can do the same sort of thing; so too listening to the responsiveness of one's own instrument. Thus, listening to listening is a way of noticing potential pathways and possibilities for response. Oliveros puts it this way: "Listening inclusively to all that can be perceived in the moment (global attention) is a way to hold the space for improvisation or the readiness to create a sounding (focused attention)" ("Improvising Composition" 82). She continues: "Readiness to sound or receive sound means that there is no prior commitment to any sound. One has to be open and ready. Any prior commitment will constitute a delay in response time or spontaneity" ("Improvising Composition" 82). 
Critical Studies in Improvisation / Études critiques en improvisation, Vol. 12, No. 2

Oliveros could be read here as suggesting the sort of suspension of habit that we have been highlighting as a crucial step in optimal experiences of site-specific improvisations. However, what are we to make of her implicit de-valuation of delay here? Oliveros seems initially to be championing the very opposite of the slowed down hesitation that we claim constitutes a nascent sensory life productive of truly responsive improvised musical collaboration and transformed relationships to place.

The way I think we should read this denigration of delayed responding is as an expression meant to foreground the action impulse contained in such receptivity, an impulse not based in previous commitment but entirely attributable to external suggestion or motive. Oliveros, as an improviser, spontaneously responds to the sounds heard, sounds that have been received and resounded by the place of performance, other performers, the audience, as well as machines and other electronic appendages. In listening to the listening, the delay or hesitation that we are pointing to is already underway. It occurs perhaps, for Oliveros, in between playing and playing more. In other words, rather than playing a pre-composed song from start to finish, there is a hesitation (this one instituted not by the performance context as such but by a commitment to improvisation), a delay, a space between playing one note and the next, one which makes room for the listening/sounding of others. Yet once this listening/sounding of others has become a fresh impetus to respond, Oliveros is accentuating the value of immediate and decisive action, an emphasis we find highlighted in a confessed desire for greater options in performance: "I experienced a new kind of performance frustration - how could I control multiple performance parameters spontaneously during improvisation when my hands and feet were too busy to access other controls" ("Tripping" 126).

Indeed, the continued elaboration of her Expanded Instrument System was based in a desire for performance gestures to be "accomplished smoothly, without breaking attention from the music" ("Tripping" 127): "Once my perception (listening) indicates a response, the parameter change needs to be available spontaneously in the interface" ("Tripping" 127).

Oliveros's interest in multiplying controls for parameters accentuates the essential coupling of listening and action. New responses arise from new ways of listening; there is no listening without an inchoate impulse towards tracing a reciprocation. Her frustration in this regard is understandable: a readiness to smoothly execute the elicited response can only be built up habitually, through practice. If Oliveros desires an immediate responsiveness to the latent sonic suggestions opened up by her listening practice, she is brushing up against an intrinsic paradox, because to go beyond the habit body is to forgo mastery and control. The awareness of an impulse to act and the ability to smoothly accomplish such actions within a performance context are not always identical.

\section{The Habit of Suspending Habit}

Perhaps, however, it is through a lifetime of such improvisatory practice linking sensory-motor coordination with a constant mandate to listen to the listening of others that such a desire could become a genuine possibility for someone such as Pauline Oliveros. After listening out of her window using the Eico tape recorder in 1953, Oliveros made a vow to, in her words, "listen to everything all the time and remind myself when I am not listening" ("Tripping" 123)..$^{7}$ Rather than instituting a change in any particular habit of listening or style of play, it would seem that the level of openness in which Oliveros sought to hold herself was one of continual deconditioned wakefulness. We might be tempted to call this a habit of suspending habit, and conversely, as our analysis has pointed to, the ceaseless spontaneous initiation of new ones. This habit of 
suspending habit would entail a degree of attentional sensitivity to the nascence of forming habit that might require vocabularies more specific to meditation to describe.

Returning to Reimer and Stein's work, we can now point to the ways in which their performances exercise this same dynamic. In Sounding the City, experiencing the musically heightened recordings from Le Champs des Possibles in tandem with the chance soundings in the area evinces the movement from inchoate suggestion (the sounds Reimer and Stein hear in these subtle sound environments) to articulated response (their electronic modification and emission back into their generative location). We are listening to their listening of the soundscape and as such, are led into a renewed perceptual relationship with it in so far as we do not habitually take suggestion from an empty field, especially one at the interstice of so many other orders of habitude (train tracks, monastic life, textile factories). As we listen to the augmented recordings, we are listening to what is not heard in the original soundscape. When, by contrast, we listen for what is not heard in the augmented recording, we hear the soundscape in its current spontaneous sounding. In other words, we listen to the soundscape as a potential, a motive. We enter a pre-habitual space, or rather, teeter on the edge between the habitual and the openness of that prepersonal layer of sensory life. Reimer and Stein's work, however, not only teeters on this ledge, but does so repeatedly: the experience is of listening to the augmented recording, and then the present soundscape, and back again. Doing this actually begins to entrench the habit of suspending habit so as to listen for and respond to new suggestion, to the extent that this can be done.

\section{Conclusion}

We started out trying to consider what the role of location is in musical experience. We looked at a particular set of performances that specifically interact with their location and tried to describe the sort of relationship to place that such performances evince. We pursued the thesis that such performances transform habitual styles of comportment by hesitantly opening to a level of sensory awareness underneath the more routinized patterns of behavior and awareness that have been amassed in everyday urban life. We pointed to such performances and the transformation they elicit as, theoretically, implied in the phenomenology of the body developed by Maurice Merleau-Ponty, which posits the co-arising of subject and world. Some have suggested that, in consequence of this essential connection, transforming the subject requires a change in the world in the form of re-location. We aim to offer an alternative in describing how musical practices of the sort performed by Reimer and Stein, as well as by Oliveros, can begin to do so on the side of both subject and world simultaneously, avoiding the necessity of relocation. Furthermore, our analysis reinforces the value of site-specific performances that take place outside of traditional venues as a way of directly implicating specific modes of comportment, rather than the more abstract patterns of body schematic orientation that are enlisted within the traditional concert hall. Because its role is not confined to individual perceptual events but instead underlies life's existential significance overall, pointing to the ways in which site-specific immersive improvisations implicate and transform the habit body, finally, necessitates a recognition of the way that particular musical experiences can have far more lasting effects on a life and its significance than the merely temporary enchantment they provide while they are occurring.

\section{Notes}

${ }^{1}$ The land was purchased from CN by the City of Montreal in 2006. 
2 http://carmelMontréal.org/

${ }^{3}$ http://www.lecarmel.org/nos-communautes/soeurs/carmelites-de-Montréal.html

4 "Consciousness is being-towards-the-thing through the intermediary of the body" (MerleauPonty, Phenomenology 139).

5 (later replaced by David Gamper)

${ }^{6}$ Merleau-Ponty, though, regards a strict division of the senses into separate streams askance.

${ }^{7}$ Oliveros does recognize the danger in such expanded listening: "We are protected from hearing all the wavings of waves in our own bodies - otherwise we might be overwhelmed by the din if we could hear our heart beating all the time, or blood rushing through arteries, cells dividing, intestinal motions, etc." ("Nature" 249).

\section{Works Cited}

Al-Saji, Alia. "'A Past Which Has Never Been Present': Bergsonian Dimensions in MerleauPonty's Theory of the Prepersonal." Research in Phenomenology, vol. 38, no. 47, 2008, pp. 41-71.

---. "A Phenomenology of Hesitation: Interrupting Racializing Habits of Seeing." Living Alterities: Phenomenology, Embodiment, and Race. State U of New York P, 2014.

Husserl, Edmund. Analyses Concerning Passive and Active Synthesis: Lectures on Transcendental Logic. Translated by Anthony J. Steinbock, Dordrecht: Springer, 2001.

Maslow, Abraham H. The Psychology of Science: A Reconnaissance. Harper \& Row, 1966.

Merleau-Ponty, Maurice. Phenomenology of Perception. Translated by Colin Smith, Humanities Press, 1962.

---. The Visible and the Invisible. Translated by Alphonso Lingis, Northwestern UP, 1968.

Mockus, Martha. Sounding Out: Pauline Oliveros and Lesbian Musicality. New York: Routledge, 2008.

Oliveros, Pauline. "The Accordion (\& The Outsider)." Sounding the Margins: Collected Writings 1992-2009. Deep Listening Publications, 2010, pp. 155-161.

---. "The Expanded Instrument System: An Introduction and Brief History." Sounding the Margins: Collected Writings 1992-2009. Deep Listening Publications, 2010, pp. 216227.

---. "Improvising Composition: How to Listen in the Time Between." Negotiated Moments: Improvisation, Sound, and Subjectivity, edited by Gillian Siddall and Ellen Waterman, Duke UP, 2016, pp. 75-90.

---. "Improvising with Spaces." Sounding the Margins: Collected Writings 1992-2009. Deep Listening Publications, 2010, pp.195-204. 
--. "Interactive Music." Sounding the Margins: Collected Writings 1992-2009. Deep Listening Publications, 2010, 4-10.

---. Interview by Alan Baker. American Mavericks. January 2003. http://musicmavericks. publicradio.org/features/interview oliveros.html Accessed 26 Oct. 2017.

---. "My 'American Music': Soundscape, Politics, Technology, Community." Sounding the Margins: Collected Writings 1992-2009. Deep Listening Publications, 2010, pp. 228245.

---. "The Nature of Listening." Sounding the Margins: Collected Writings 1992-2009. Deep Listening Publications, 2010, pp. 248-249.

---. "Tripping on Wires: The Wireless Body - Who is Improvising?" Sounding the Margins: Collected Writings 1992-2009. Deep Listening Publications, 2010, pp. 121-127.

---. "Virtual and Acoustic Space as a Dynamic Parameter of Music." Leonardo Music Journal, vol. 5, 1995, pp. 12-22.

Stubley, Eleanor. Personal interview. May 2017.

Sullivan, Shannon. Revealing Whiteness: The Unconscious Habits of Racial Privilege. Indiana UP, 2006. 